\title{
Impact of Global Warming on Intensity-Duration-Frequency (IDF) Relationship of Precipitation: A Case Study of Toronto, Canada
}

\author{
Erick Carlier, Jamal El Khattabi \\ Polytech'lille, Laboratoire de Génie Civil et Géo-Environnement (LGCgE), Université Lille 1, Sciences et \\ Technologie, Villeneuve d'Ascq, France \\ Email: erick.carlier@polytech-lille.fr
}

Received 27 May 2015; accepted 9 January 2016; published 12 January 2016

Copyright ( 2016 by authors and Scientific Research Publishing Inc.

This work is licensed under the Creative Commons Attribution International License (CC BY).

http://creativecommons.org/licenses/by/4.0/

(c) (i) Open Access

\begin{abstract}
Annual maximum rainfall intensity for several duration and return periods has been analyzed according to the Gumbel distribution. The Intensity-Duration-Frequency (IDF) curves before and after 1980 have been computed and compared. For the city of Toronto, it is shown that the rainfall intensities after 1980 are lower than those from before this date. This is especially clear for those of short duration. Comparing our results with those of other authors, it appears that, for the moment, no general law on the impact of global warming on the curves intensity duration frequency cannot be made. It appears that the impact of global warming on rainfall varies with geographic location and that it is not possible to draw some general conclusions across the planet.
\end{abstract}

\section{Keywords}

Climate Change, Duration, Frequency, Intensity, Rainfall

\section{Introduction}

Regarding civil engineering, the knowledge and understanding of climate change is important because, if there are changes in the variables related to hydrological systems, it could imply changes in design criteria, as these are frequently based upon the assumption of the hydrological series stationary. Not doing so, could mean the under or over design of hydraulic infrastructures, thus creating performance deficiencies or over expensive solutions. 
The IDF (Intensity Duration Frequency) relationship constitutes an objective tool to quantify precipitation uncertainty, especially in circumstances when a design rainfall event must be determined for a particular water resources project. To perform the analysis, long-term precipitation data from a recording rain gage must be available. The prediction of uncertain environmental variables is often a hydrologic problem of significance in water resources management and water resources design projects. The Gumbel distribution, named after one of the pioneer scientists in practical applications of the Extreme Value Theory (EVT), the German mathematician Emil Gumbel (1891-1966), has been extensively used in various fields including hydrology for modeling extreme events [1]-[3]. Gumbel applied EVT on real world problems in engineering and in meteorological phenomena such as annual flood flows [4].

Figure 1 shows that the temperature increases significantly since 1980. The objective of this present work is to study the impact of this increase on the intensity of the rainfall at Toronto for several return periods and durations.

\section{Statistical Analysis of the Rainfall}

The Gumbel distribution is very suitable for modeling extreme event [5] [6]. The cumulative distribution function (CDF) is given by Equation (1):

$$
F_{X}(x)=P(X \leq x)=\exp \left(-\exp \left(-\frac{x-a}{b}\right)\right)
$$

where $X$ is a random variable. In our case, $X$ is the rainfall intensity or the rainfall depth for a given duration.

The Gumbel variable is defined by Equation (2)

$$
u=\frac{x-a}{b}
$$

The parameters $a$ and $b$ are defined by:

$$
\begin{aligned}
& b=\frac{\sqrt{6}}{\pi} \sigma \\
& a=\mu-b \gamma
\end{aligned}
$$

where $\sigma$ is the standard deviation and $\mu$ is the mean of the variable.

The empirical distribution of Hazen is used:

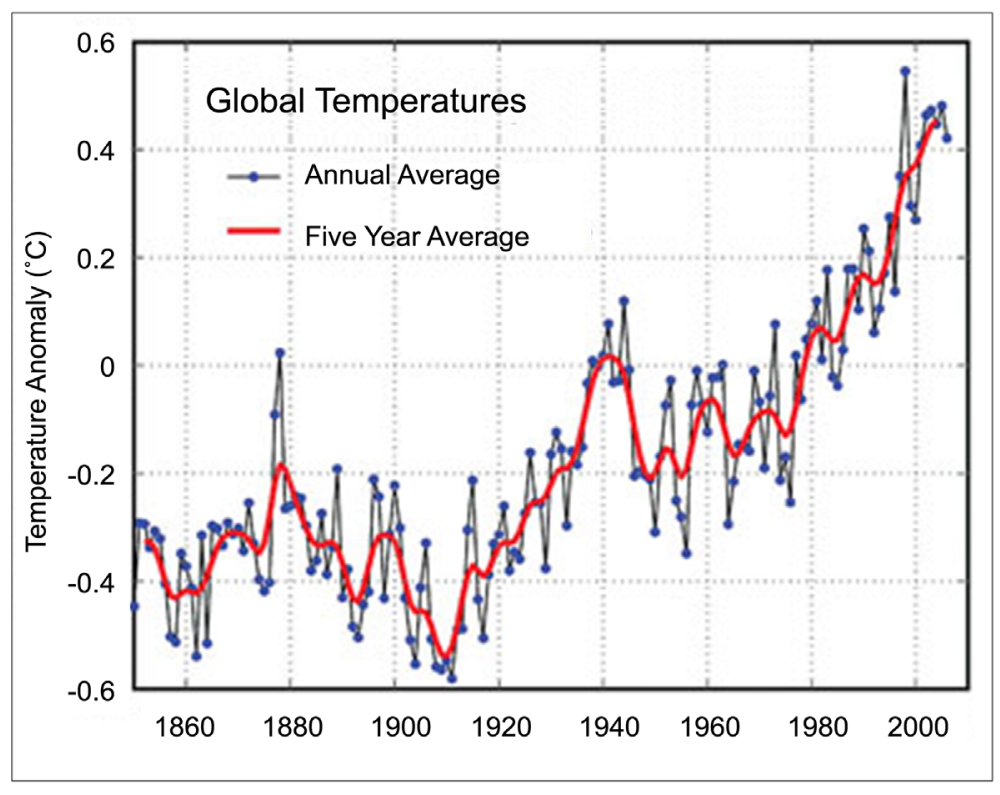

Figure 1. Global temperature anomaly (source: Institute Creation Research (ICR)). 


$$
F\left(x_{i}\right)=P\left(i \leq x_{i}\right)=\frac{i-0.5}{n}
$$

where $i$ is the rank of a given data and $n$ is the total number of data.

The rainfall data of Toronto (Canada) has been used for computing the IDF curves before and after 1980 .

The rainfall data are from 1940 to 2007. The rainfall station is located at latitude $43.67^{\circ} \mathrm{N}$ and longitude $79.4^{\circ} \mathrm{W}$. Its elevation is $112 \mathrm{~m}$. The duration of rainfall are $5 \mathrm{~min}, 10 \mathrm{~min}, 15 \mathrm{~min}, 30 \mathrm{~min}, 1 \mathrm{~h}, 2 \mathrm{~h}, 6 \mathrm{~h}, 12 \mathrm{~h}$ and $24 \mathrm{~h}$. Equation (2) shows that if the Gumbel distribution is valid, it has to a linear relationship between the empirical intensity $x$ and the Gumbel variable $u$.

\section{Validity of the Gumbel Distribution}

Starting from Equation (4), the Gumbel variable is computed by:

$$
u=-\ln \left[-\ln \left(\frac{i-0.5}{n}\right)\right]
$$

where $\ln$ is the natural logarithm, $i$ is the rank of a given data and $n$ is the total number of data.

Figure 2 shows the experimental rainfall depth versus the Gumble variable. The fit of the data by the Gumbel distribution is suitable.

\section{The IDF curves}

The IDF curves are computed for five return periods $T(2,5,10,20$ and 50 years). For these return periods, the probability associated with the not exceedance is computed by:

$$
P(X<x)=1-\frac{1}{T}
$$

The Gumbel variable are computed by:

$$
u=-\ln \left[-\ln \left(\frac{i-0.5}{n}\right)\right]
$$

Table 1 gives the results of Equations (6) and (7).

For each rainfall duration, there are a specific standard deviation $\sigma$ and a specific mean $\mu$. Therefore, there are a specific parameters $a$ and $b$ defined by Equation (3).

Table 2 and Table 3 give the different values of these parameters.

Equation (2) enable to compute the rainfall depth $x$ for the different durations and return periods. Finally, the rainfall intensity is calculated by dividing the rainfall depth by the duration. Table 4 and Table 5 give the computed intensity before and after 1980 and Figures 3-7 shows the IDF curves.

Examination of Table 4 and Table 5, and Figures 3-7, it appears that the impact of global warming on the IDF curves is not very clear, however, their analysis enables to note that the rainfall intensities after 1980 are lower than those from before this date.

Table 1. Gumbel variables for several return periods.

\begin{tabular}{cccccc}
\hline Return periods (year) & 2 & 5 & 10 & 20 & 50 \\
\hline $\begin{array}{c}\text { Probability associated with the not } \\
\text { exceedance }\end{array}$ & 0.5 & 0.8 & 0.9 & 0.95 & 0.98 \\
\begin{tabular}{c} 
Gumbel variable \\
\hline
\end{tabular} & 0.36651292 & 1.49993999 & 2.25036733 & 2.97019525 & 3.90193866 \\
\hline
\end{tabular}

Table 2. Values of the gumbel variable parameters for several durations (5 min - $1 \mathrm{~h}$ ).

\begin{tabular}{cccccc}
\hline Duration & $5 \mathrm{~min}$ & $10 \mathrm{~min}$ & $15 \min$ & $30 \mathrm{~min}$ & 20.9852459 \\
\hline Mean & 9.76393443 & 13.4672131 & 16.5032787 & 25.4163934 \\
Standard deviation & 4.02181687 & 4.81233558 & 6.60978989 & 8.77967038 & 10.0157573 \\
$b$ & 3.13738827 & 3.75406581 & 5.15624603 & 6.84895304 & 7.81321486 \\
$a$ & 7.95303392 & 11.3003663 & 13.5270935 & 17.0320302 & 20.9066058 \\
\hline
\end{tabular}


Table 3. Values of the gumbel variable parameters for several durations (2 h - $24 \mathrm{~h})$.

\begin{tabular}{ccccc}
\hline Duration & $2 \mathrm{~h}$ & $6 \mathrm{~h}$ & $12 \mathrm{~h}$ & $24 \mathrm{~h}$ \\
\hline Mean & 29.6983607 & 36.59 & 43.3305085 & 48.3409836 \\
Standard deviation & 10.6580563 & 12.7690662 & 13.7554786 & 14.7781976 \\
$b$ & 8.31426738 & 9.96104988 & 10.7305426 & 11.5283578 \\
$a$ & 24.8993655 & 30.840482 & 37.1368393 & 41.6868155 \\
\hline
\end{tabular}

Table 4. Rainfall intensity before 1980 for several durations and return periods.

\begin{tabular}{cccccc}
\hline Intensity mm/h & 2 years & 5 years & 10 years & 20 years & 50 years \\
\hline $5 \mathrm{~min}$ & 113.4117503 & 161.4166204 & 193.2000214 & 223.6874228 & 263.1502366 \\
$10 \mathrm{~min}$ & 77.58690533 & 105.544399 & 124.0546925 & 141.8102105 & 164.7929072 \\
$15 \mathrm{~min}$ & 62.53175359 & 87.23827087 & 103.5961351 & 119.2869912 & 139.5971949 \\
$30 \mathrm{~min}$ & 40.15905929 & 55.73317723 & 66.04459846 & 75.93556127 & 88.73839806 \\
$1 \mathrm{~h}$ & 24.92161479 & 33.28195029 & 38.81721985 & 44.1267833 & 50.99946856 \\
$2 \mathrm{~h}$ & 14.73000025 & 19.2794554 & 22.29159057 & 25.18090295 & 28.92082144 \\
$6 \mathrm{~h}$ & 6.084464197 & 7.9127997 & 9.123316892 & 10.28447405 & 11.78747288 \\
$12 \mathrm{~h}$ & 3.611399512 & 4.608573879 & 5.268790077 & 5.902085304 & 6.721821017 \\
$24 \mathrm{~h}$ & 2.012225697 & 2.541975305 & 2.89271564 & 3.229154191 & 3.664639384 \\
\hline
\end{tabular}

Table 5. Rainfall intensity after 1980 for several durations and return periods.

\begin{tabular}{cccccc}
\hline Intensity mm/h & 2 years & 5 years & 10 years & 20 years & 50 years \\
\hline $5 \mathrm{~min}$ & 103.1542708 & 135.6783017 & 157.2120401 & 177.867719 & 204.6043765 \\
$10 \mathrm{~min}$ & 73.74453206 & 95.29262978 & 109.5593454 & 123.2443216 & 140.9581195 \\
$15 \mathrm{~min}$ & 60.28632165 & 81.87858867 & 96.17454824 & 109.8875759 & 127.6376836 \\
$30 \mathrm{~min}$ & 37.38801884 & 53.05351799 & 63.42544152 & 73.37443959 & 86.25239708 \\
$1 \mathrm{~h}$ & 22.0043123 & 31.57485927 & 37.91139413 & 43.98955049 & 51.85710044 \\
$2 \mathrm{~h}$ & 12.8216983 & 17.70357911 & 20.935809 & 24.03624151 & 28.04943337 \\
$6 \mathrm{~h}$ & 5.218241187 & 7.131638583 & 8.39847415 & 9.61365324 & 11.18657793 \\
$12 \mathrm{~h}$ & 3.132853403 & 4.139250597 & 4.805573109 & 5.44472566 & 6.272043077 \\
$24 \mathrm{~h}$ & 1.76292092 & 2.314501059 & 2.679695105 & 3.029998002 & 3.483429171
\end{tabular}

This is especially clear for those of short duration. Their intensity decreased, particularly for the return period of 5, 10, 20 and 50 years.

\section{Conclusions}

Examination of Table 4 and Table 5, and Figures 3-7, it appears that the rainfall intensities after 1980 are lower than those from before this date. This is especially clear for those of short duration.

Fallot and Hertig [7] carried out Gumbel analysis of rainfall depth at 429 locations in Switzerland. They computed rainfall depth for a return period of 500 years and concluded that rainfall depth obtained for the period 1961 to 2010 are overall higher than 15\% than estimated from the rainfall series from 1901 to 1970 for all stations in Switzerland. Vaz [8] studied annual maximum daily rainfall series from 23 rain gages in Portugal. 
validity of the Gumbel distribution

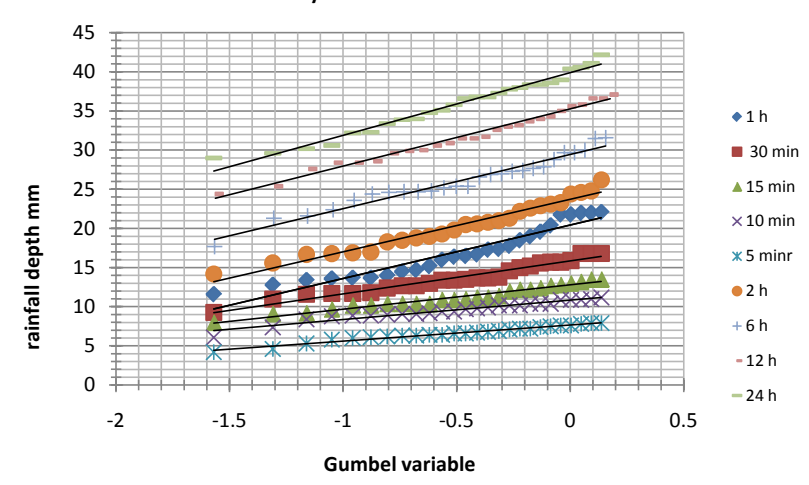

Figure 2. Validity of the Gumbel distribution.

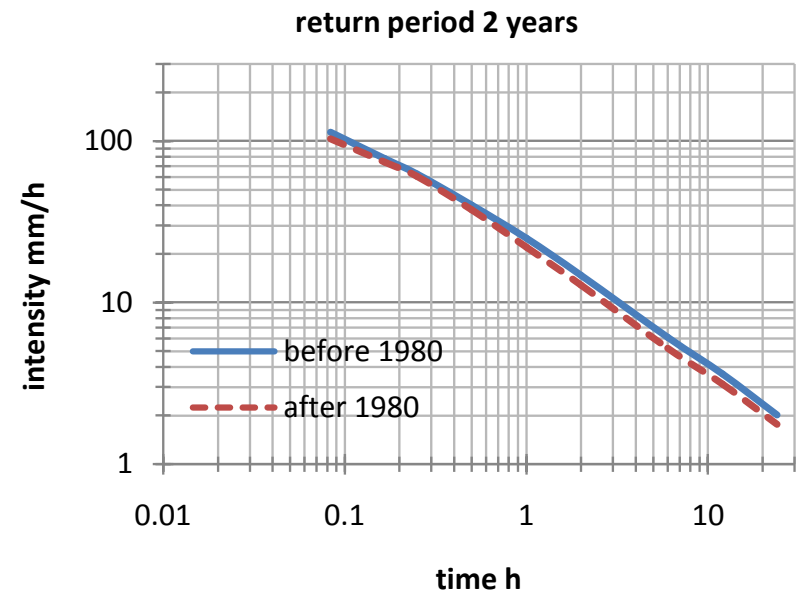

Figure 3. IDF curves before and after 1980. $\mathrm{T}=2$ years.

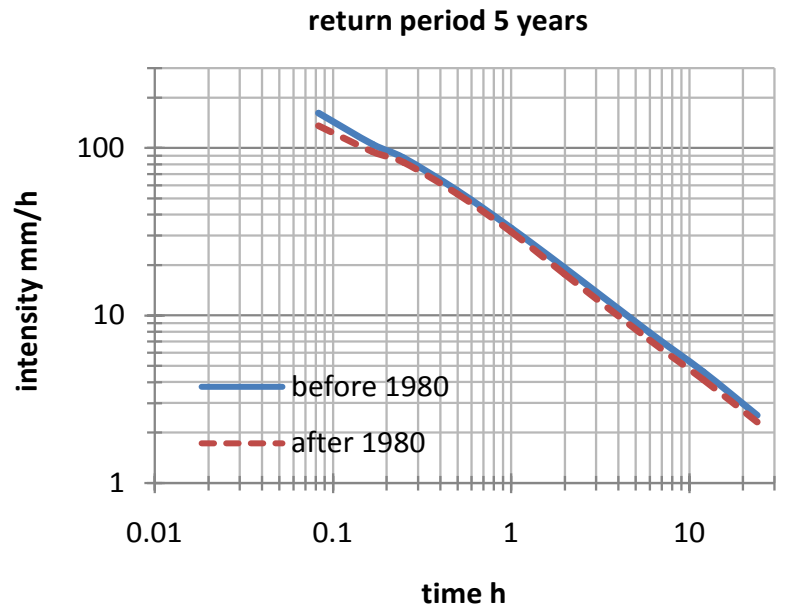

Figure 4. IDF curves before and after 1980. $T=5$ years.

The research carried out showed that the samples of intensive rainfalls do not exhibit trends, as to affirm or contradict the effects often attributed to the climate change phenomenon (i.e. heavier rainfalls with smaller duration). The study found out that all kinds of behaviors can occur: some samples denote the trends often considered as resulting from the climate change, while exhibit the exact opposite, not allowing the identification of any of the consequences attributed to such phenomenon. 


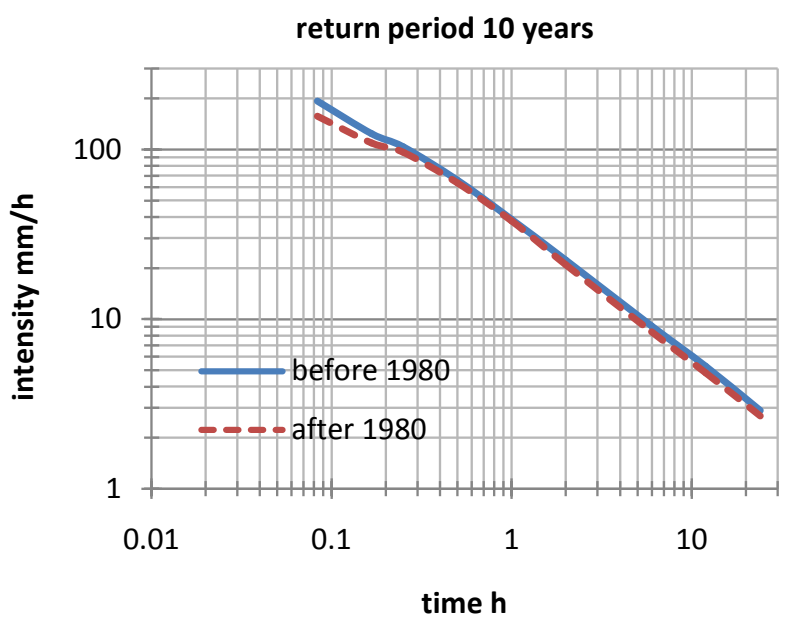

Figure 5. IDF curves before and after $1980 . \mathrm{T}=10$ years.

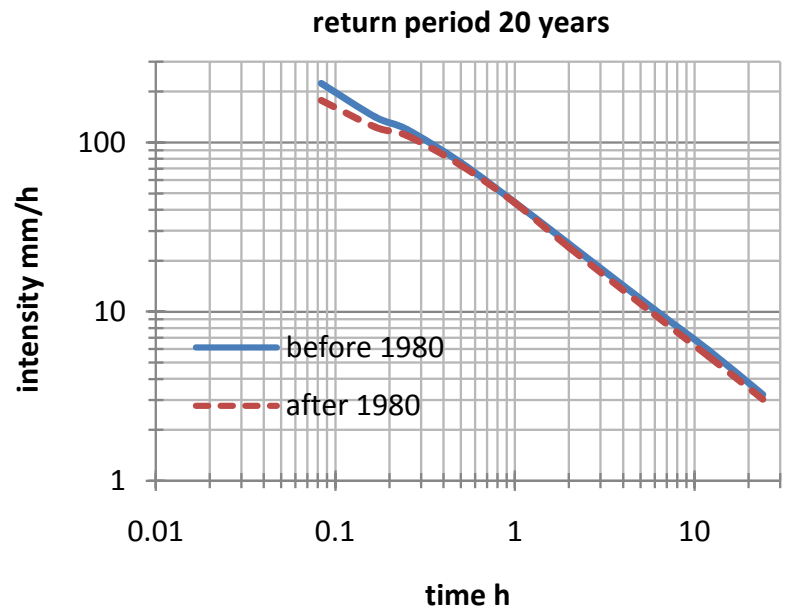

Figure 6. IDF curves before and after $1980 . T=20$ years.

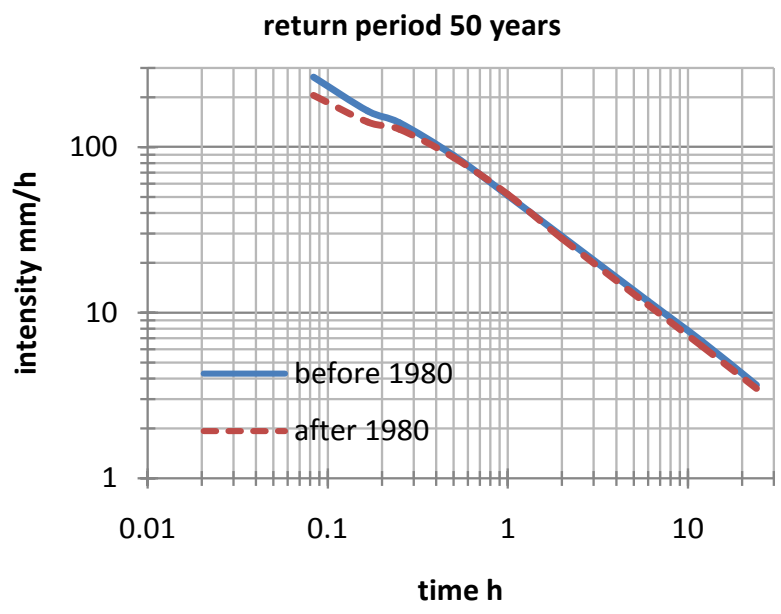

Figure 7. IDF curves before and after $1980 . T=50$ years.

Comparing our results with those of other authors, it appears that, for the moment, no general law on the impact of global warming on the intensity duration frequency relationships can be made. It appears that the impact 
of global warming on rainfall varies with geographic location and that it is not possible to draw some general conclusions across the planet

\section{References}

[1] Al-anazi, K. and El-sebaie, I. (2013) Development of Intensity-Duration-Frequency Relationships for Abha City in Saudi Arabia. International Journal of Computational Engineering Research, 3, 58-65.

[2] Rizwan, M. and Tae-Woong, K. (2013) Application of a Mixed Gumbel Distribution to Construct Rainfall DepthDuration-Frequency (DDF) Curves Considering Outlier Effect in Hydrologic Data. Journal of Environmental Science, Toxicology and Food Technology, 6, 54-60.

[3] Solaiman, T.A. and Simonovic, S.P. (2011) Development of Probability Based Intensity-Duration-Frequency Curves under Climate Change. Water Resources Research Report, The University of Western Ontario, 93 p.

[4] Gumbel, E.J. (1958) Statistics of Extremes, Columbia University Press, New York.

[5] Haan, C.T. (1989) Statistical Methods in Hydrology, Prentice Hall, Eglewood Cliffs.

[6] Kottega, N.T. (1980) Stochastic Water Resources Technology. Macmillan Press, London. http://dx.doi.org/10.1007/978-1-349-03467-3

[7] Fallot, J.M. and Hertig, J.A. (2013) Détermination des precipitations extremes en Suisse à l'aide d'analyses statistiques et augmentation des valeurs extrêmes durant le 20 ème siècle. Mémoires de la Société Vaudoise des Sciences Naturelles, 25, 23-34.

[8] Vaz, C.M. (2008) Trend Analysis in Annual Maximum Daily Rainfall Series. Thesis. Instituto superior técnico, Universidade Técnica de Lisboa. 